\title{
Spitz nevus and Reed nevus
}

Nevo de Spitz e nevo de Reed

Alessandra Yoradjian
Francisco Macedo Paschoal

\begin{abstract}
Spitz and Reed nevi, also called spindle and/or epithelioid cell nevi, are a special group of melanocytic lesions due to their peculiar clinical, dermoscopic and histopathological features. The study of these nevi is of great interest because both their nomenclature and classification are still a matter of discussion. Most importantly, the difficulty to differentiate them from melanoma can lead to inadequate therapies. In this context, dermoscopy, a link between clinical and anatomopathological examinations, appears as a helpful diagnostic tool whose accuracy can reach 93\%. "Borderline" lesions are still a great challenge and object of research, including molecular studies. The present study explores the relevant characteristics of these nevi, with emphasis on dermoscopic findings, aiming at understanding their natural history, as well as discussing treatment and patient follow-up.
\end{abstract}

Keywords: Dermoscopy; Melanoma; Nevus, epithelioid and spindle cell

Resumo: Os nevos de Spitz e de Reed, ou também chamados nevos de células fusiformes e/ou epitelióides, formam um grupo especial de lesões melanocíticas, por suas características peculiares, tanto clínicas como dermatoscópicas e histopatológicas. Torna-se grande o interesse no estudo desses nevos, pois tanto a nomenclatura como a classificação ainda são motivos de debate e, sobretudo, a dificuldade de diferenciação com o melanoma pode gerar condutas terapêuticas inadequadas. Neste contexto, surge a dermatoscopia, elo entre o exame clínico e o anatomopatológico, como método diagnóstico auxiliar importante cuja acurácia pode chegar a 93\%. A grande dificuldade ainda são as lesões "borderline", motivo de pesquisas, incluindo estudos moleculares. O presente estudo aborda os aspectos relevantes das características destes nevos, com ênfase nos achados dermatoscópicos, buscando o entendimento da sua história natural, além da discussão quanto ao tratamento e seguimento dos pacientes. Palavras-chave: Dermoscopia; Melanoma; Nevo de células epitelióides e fusiformes

\footnotetext{
Received on 07.12.2010.

Approved by the Advisory Board and accepted for publication on 04.04.2011 Work conducted at ABC School of Medicine (FMABC) - Santo André (SP), Brazil.

Conflict of interest: None

Financial funding: None

Dermatologist; Volunteer at ABC School of Medicine (FMABC) - Santo André (SP), Brazil.

PhD in Pathology - Dermatopathologist, Department of Pathology and Dermatology, Universidade Federal de São Paulo (Federal University of Sao Paulo) (UNIFESP) - Sao Paulo (SP), Brazil.

PhD in Health Sciences - Assistant Professor of Dermatology, Faculdade de Medicina do ABC (ABC School of Medicine) (FMABC) - Santo André (SP), Brazil.

(C)2012 by Anais Brasileiros de Dermatologia
} 


\section{INTRODUCTION}

Spitz and Reed nevi are melanocytic lesions whose clinical, dermoscopic and histopathological presentations may resemble those of melanoma. The knowledge and study of both entities is essential to establish correct diagnosis. On histopathological examination, the "typical" Spitz nevus (as it is called by some authors) has features that are different from those of melanoma. Melanomas that are similar to Spitz nevus ("Spitz-like" melanomas) with histopathological criteria that help make this distinction have also been described. Borderline lesions are a great challenge. These lesions have histological characteristics of Spitz nevus and melanoma and are therefore often referred to as melanocytic lesions of uncertain biological potential (possibly melanoma), presenting controversies with regard to diagnosis and treatment. In this review article we discuss the clinical, dermoscopic and histopathological presentations of these nevi, as well as the controversies found in the literature.

\section{HISTORY}

Spitz nevus was first described in detail by Sophie Spitz in 1948 as "melanoma of childhood" because it presented, according to what was known at the time, histopathological features of malignancy, but with peculiar characteristics. ${ }^{1-8}$ Later, Arthur C. Allen (1953) included juvenile melanoma in the category of benign melanocytic lesions due to its benign biological behavior, although it presented a cytoarchitecture that was similar to that of melanoma. ${ }^{6-10}$ These two authors classified Spitz nevus as a distinct type of nevus. ${ }^{6}$ In 1954, Helwig argued that the term "juvenile melanoma" was inappropriate because it could also occur in adults, not to mention the fact that the term melanoma has a malignant connotation. He suggested the term spindle-cell nevus. ${ }^{4,5}$ Some studies have questioned the use of the term "nevus" to refer to these lesions, since this term corresponds to a benign lesion and Spitz nevi may show atypia. Therefore, they suggested a more neutral terminology such as "lesion," including all "Spitz lesions". Another suggestion is to call it "Spitz tumor", differentiating the entity from nevi and melanoma. However, there is still no consensus in the literature. ${ }^{8}$

In 1975, Reed et al ${ }^{7,11-15}$ described a deeply pigmented melanocytic lesion, also benign, found especially in the lower extremities of young adults. Some authors consider it as a single nosological entity, but others refer to it as a pigmented variant of the classic Spitz nevus, with its own clinical and histological features. ${ }^{6,7,11,12,13,14,16,17}$ Whether Spitz and Reed nevi are distinct lesions is still debatable. ${ }^{6}$ For this reason, some authors try to differentiate them in histological types, but there are controversies, as the combination of their microscopic characteristics is very common. ${ }^{7}$ The term spindle and epithelioid cell nevus, introduced by Kernen and Ackerman in 1960, is currently adopted in an attempt to unify their diagnostic features. ${ }^{4,7}$

\section{CLINICAL ASPECTS}

Spitz nevus usually presents as a solitary, rounded or oval papule, with a smooth surface. It may also be verrucous, with mild scaling, crusting, or erosion. Ulceration is rare and is more common in melanoma. ${ }^{9}$ Its color can vary from pink to reddish-brown or purple-red and its growth may be slow or fast. ${ }^{5,6,18}$ The lesion is often asymptomatic and bleeding and itching rarely occur. ${ }^{19}$ It appears in the first two decades of life, although it may appear in adulthood in $1 / 3$ of the cases. It is rare at birth. ${ }^{5,7.8}$ It corresponds to $1 \%$ of the excised nevi in childhood. ${ }^{8}$ It mainly affects the face or extremities, with a diameter generally smaller than one centimeter (Figure 1). Evolution time, from its onset until diagnosis, can vary from weeks to years, and the typical presentation in childhood is the development of a pink or reddish (due to lack of melanin) fast growing papule, located in the head or neck. ${ }^{6,7,13}$ In adults, it usually presents as a brown or black papule or plaque located in the trunk or lower limb, being pigmented in $72 \%$ of the cases and infrequent in the palmoplantar region. ${ }^{1,6,20}$ Hypopigmented lesions can be mistaken by amelanotic melanoma and its polypoid variant shows similarities with polypoid melanoma. ${ }^{6,10}$ Caucasians seem to be the most affected race, with a higher but discreet incidence in women, perhaps due to the fact that they seek more medical care for cosmetic reasons. ${ }^{3,5,6,8}$ The incidence of melanocytic nevi is estimated to vary between $1-10 \%$ in childhood. ${ }^{5}$ Less common variants, such as halo, combi-

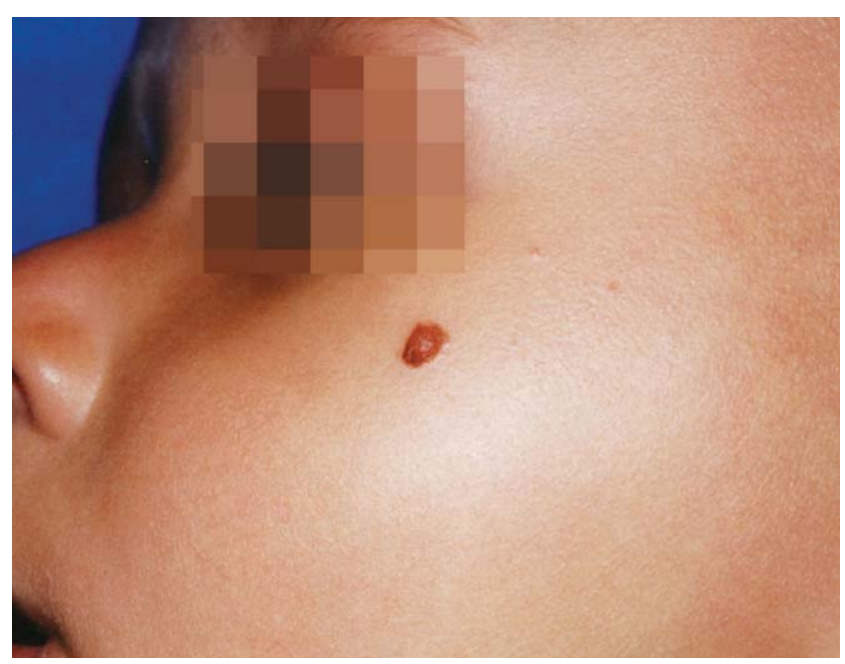

Figure 1: Clinical aspect of the classic Spitz nevus 
ned, dysplastic, multiple disseminated, and agminated nevi have been described. ${ }^{4,5,6,8}$ Even in cases of multiple lesions, regression is natural over the course of time. A possible explanation for the development of multiple lesions would be the potential to spread to other skin sites, but with limited growth and permanence, tending to spontaneous involution because of its benign biological behavior. ${ }^{4}$ Melanocytic nevus cells may be present in the lymph nodes, but their significance demands further investigation, considering that lymph nodes are not usually excised and examined at the diagnosis of spindle and/or epithelioid cell nevus. ${ }^{4}$

Reed nevus is characterized by a dark brown or black papule or plaque, often affecting the lower limbs of young women around the third decade of life; however, it can occur in children and young adults of both sexes (Figure 2). ${ }^{11,14,16,21}$ It is usually smaller than Spitz nevus. ${ }^{16}$ It can grow fast. Less frequently, it may present as hypo-or amelanotic. ${ }^{13.21}$ Pathologists occasionally find lesions composed of nests of spindle-shaped melanocytes located in the epidermis and papillary dermis with or without a minimum amount of melanin. In a review of 349 cases of Spitz and Reed nevus, five cases of the hypopigmented variant of Reed nevus were found. ${ }^{13}$

The main differential diagnoses are Clark's nevus, dermatofibroma, angioma, pyogenic granuloma, primary adnexal tumor, solitary mastocytoma, pseudolymphoma and melanoma. ${ }^{6,8}$

\section{DERMOSCOPIC ASPECTS}

Due to the frequent difficulty to clinically differentiate these lesions from melanoma, dermoscopy appears as a noninvasive and valuable method to improve diagnostic accuracy. ${ }^{19,20,22-24}$ New knowledge

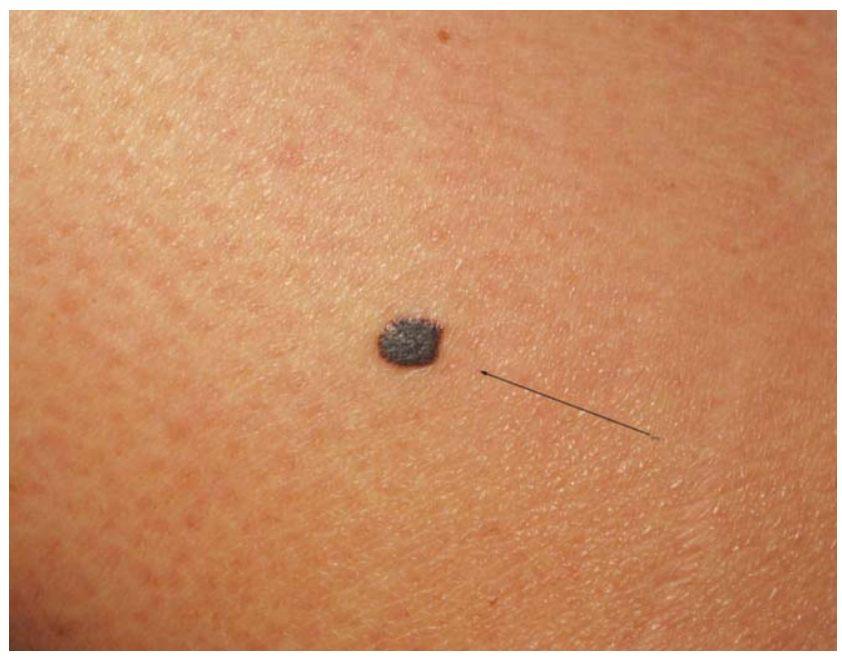

Figure 2: Clinical aspect of the classic Reed nevus has been recently acquired, and dermoscopy has become an important link between clinical and histopathological examination, since the technique allows visualization of morphological structures not discernible to the naked eye. ${ }^{7,25,26}$ Despite its depth limitation - dermoscopy allows the analysis of structures up to the superficial dermis - it shows high sensitivity and specificity in the preoperative diagnosis of pigmented lesions. ${ }^{26}$ It is based on the physical principle of reducing the reflection of light through the stratum corneum. It is also called dermatoscopy, surface microscopy and epiluminescence microscopy. ${ }^{7,18,27}$

Three main dermoscopic patterns have been recognized: ${ }^{1,8,14}$

1 - Starburst pattern, observed in 53\% of the cases. This is a pattern with prominent central pigmentation, diffuse, bluish-gray or black, also called black lamella, corresponding to the region of greatest parakeratosis, and streaks distributed around the lesion that correlate to areas of cell nest compression observed in histopathology. ${ }^{14} 19.4 \%$ of the cases have regular and prominent pigment network, and 8.3\%, have a bluish-black pigmentation without streaks in the periphery (Figures 3 and 4 ).

2 - globular pattern (coffee bean-like appearance), present in $22 \%$ of the cases. It is characterized by a brownish-bluish-gray center and periphery with large brown globules; dots and globules can be distributed throughout the lesion. "Dotted" vessels are also observed (Figure 5).

3 - Atypical pattern, found in $25 \%$ of the cases. There is uneven distribution of colors and structures, and it may resemble a blue-white veil (hyperplasia of the epidermis associated with the presence of melanophages in the dermis) or black blotches; there is also peripheral radiate streaks and dotted vascular

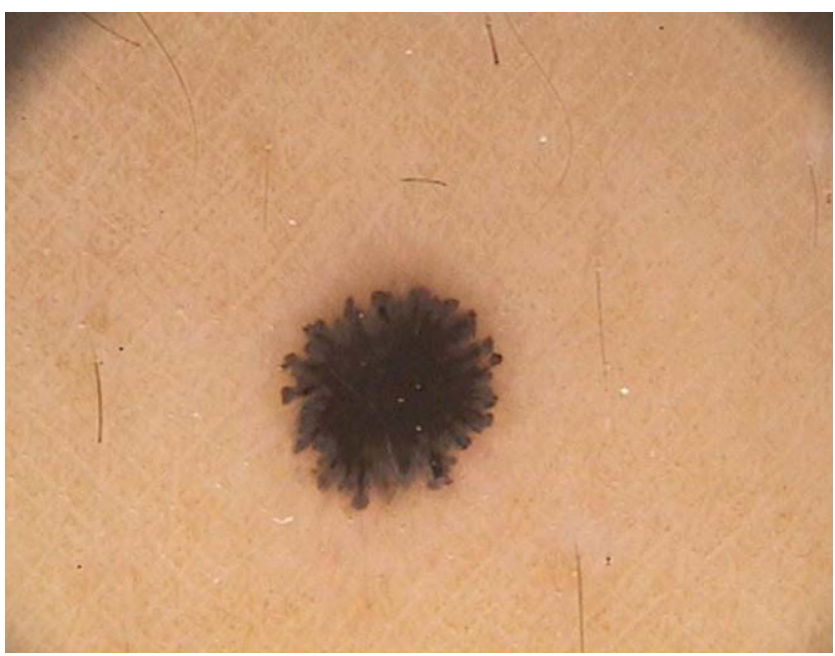

FIGURE 3: Starburst dermoscopic pattern of Reed nevus 


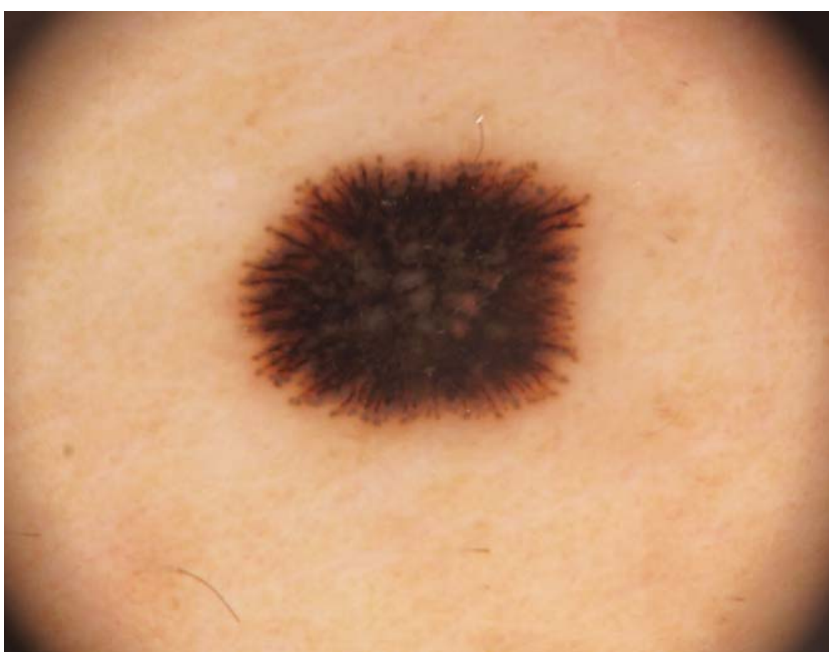

FiguRE 4: Starburst dermoscopic pattern of Reed nevus

pattern (Figures 6). 1,6,23,26,28,29

In hypopigmented Spitz nevus, the most prominent feature is the vascular pattern, characterized by the presence of dotted and comma-shaped vessels, making it difficult to differentiate them from amelanotic melanoma. ${ }^{6,26}$

Another recent finding, found in $10.5 \%$ of the cases, is the superficial black network. It consists of a structure similar to the pigment network, prominent, black, ending in the periphery and resting on a bluishwhite to bluish-black diffuse pigment network. It corresponds, on histopathological examination, to focal areas of pigmented parakeratosis (small blocks of highly pigmented melanin in the stratum corneum, easily extracted with adhesive tape) that yield a black, reticulated appearance in the horizontal plane. This may reflect a functional characteristic that translates into increased pigment synthesis by melanocyte nests.
${ }^{12,22}$ Large amounts of melanin can also be found in the papillary dermis within melanocyte nests and numerous melanophages, probably correlating with the bluish-black background seen in these lesions. ${ }^{6,22}$ The superficial black network may be a dermoscopic feature especially useful for the diagnosis of these nevi. ${ }^{22}$

Furthermore, we can observe central reticular depigmentation in pigmented Spitz nevi, also known as reverse pigment network. ${ }^{19,28,30}$

In melanoma, the lesion is asymmetrical, the pigment network is often atypical, dots, globules and streaks are irregular, there may be pseudopods and blue-white veil, and varied and uneven pigmentation. There are difficult, atypical cases, in which the differential diagnosis with melanoma becomes complicated, not only clinically and histopathologically, but also in dermoscopy. ${ }^{28}$

In 2002, Pizzichetta et al. proposed a developmental sequence for these nevi with the progressive transformation of the globular pattern into starburst; this, in turn, evolved into a homogeneous pattern (disappearance of the lesion when it becomes stable). Therefore, it is believed that the patterns are, in fact, steps in the evolution process of the same lesion and not distinct clinical and pathological entities. ${ }^{1,6,7,14,18,20,24}$ This may explain the rare presentation of the disease in the elderly, as these nevi may undergo a process of gradual involution over the years. ${ }^{24}$ This is also consistent with observations of a previous study in which the cell maturity observed at the base of the lesion was more often seen in adults than in children, suggesting a development and stabilization process of these nevi. Reduced suprabasal epidermal involvement was observed in Spitz nevi of adults compared to those found in children, which is likely the result of their gradual involution. ${ }^{3,5}$ It was found that the main patterns observed (66\%) were starburst, globular and aty-

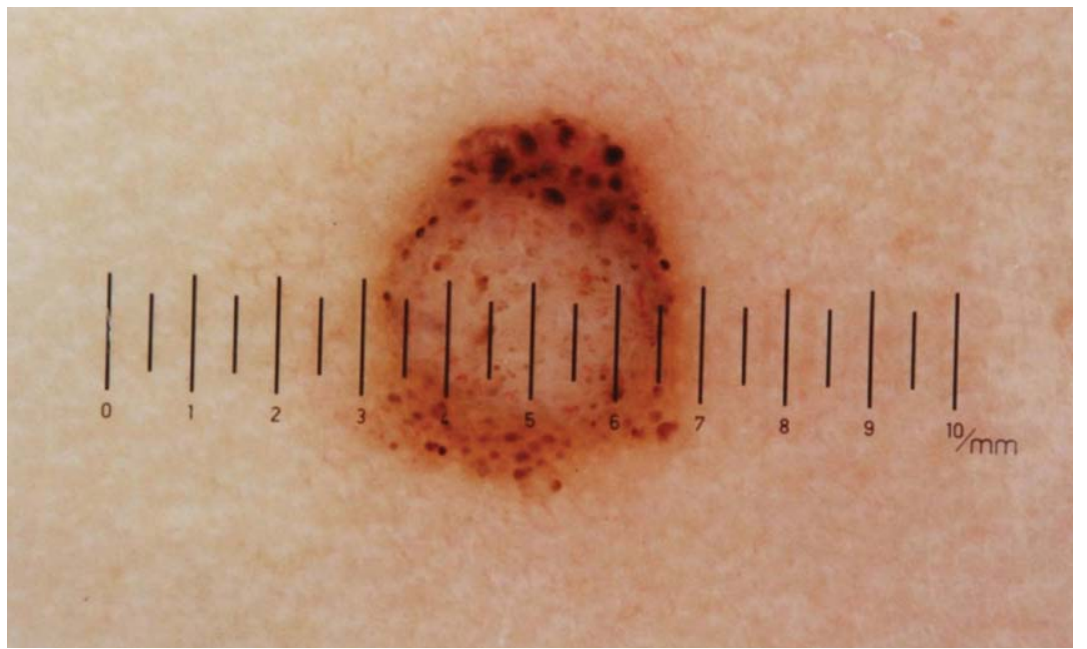

Figure 5: Globular dermoscopic aspect (coffee bean-like appearance) of Spitz nevus 

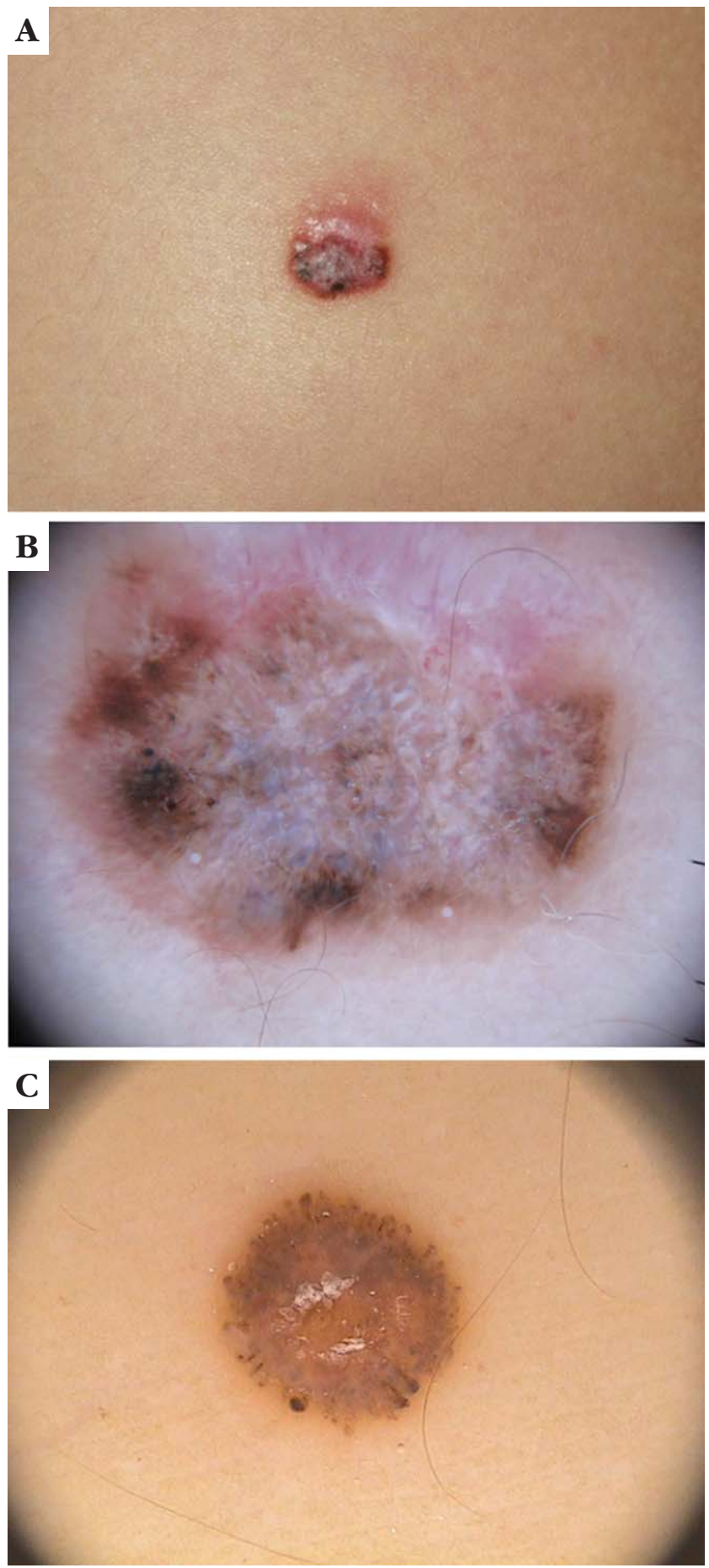

FIGURE 6: A. Clinical aspect of atypical Spitz nevus, B. Dermoscopic aspect of atypical Spitz nevus (dermoscopy of the clinical lesion shown in Figure 6A); C. Atypical dermoscopic pattern of Reed nevus

pical, confirming literature data. However, this study has shown that there was no predominance of any pattern among the established histological subtypes, corroborating data from studies by Pizzichetta. Although previous studies have reported a higher fre- quency of the "starburst" pattern in Reed nevus, the progression model of evolution suggests that, in most cases, the clinicopathological distinction between Spitz and Reed nevi cannot be properly established, thus not presenting clinical relevance. ${ }^{7,24}$

\section{HISTOPATHOLOGICAL ASPECTS}

Spitzoid lesions, like other melanocytic lesions, can be histologically benign, atypical and malignant. After examination of these lesions under the microscope, we can attempt to classify them into 3 categories:

1. Spitz nevus without other abnormalities

2. Spitz nevus with one or more aspects of atypia (atypical Spitz nevus)

\section{Spitzoid melanoma}

Spitz nevi, in their majority (approximately $66 \%$ ) are compound ${ }^{8}, 5-10 \%$ junctional and $12-20 \%$ dermal. ${ }^{1,31}$

The architectural aspect of the lesion includes symmetry, size smaller than $1.0 \mathrm{~cm}$, cell maturation, shallow depth and little or no pagetoid dissemination (epidermotropism), as shown in Figure 7.

\section{Spitz nevus}

The classical Spitz nevus has the configuration of a wedge whose base points to the epidermis. It is symmetrical, with well-defined margins, little pigmentation and vascular and desmoplastic stroma. Fascicles are often grouped in the connective tissue of hair follicle sheaths, and melanocytic cells in these regions are larger and more atypical. Outside the fascicles, cells are round, epithelioid. Variations may occur, there may be marked atypia and nuclear pleomorphism. The presence of cell maturation at the

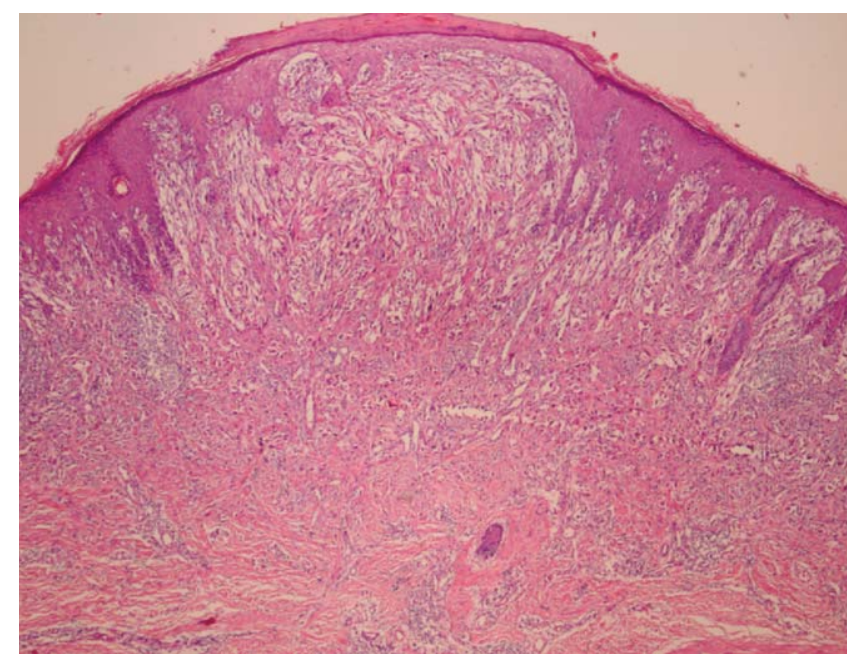

FIGURE 7: Spitz nevus in lower magnification - architecture of the lesion, symmetry and wedge-like shape with the base pointing to the epidermis (HE, 40x) 
base of the tumor may be a feature in the histological differentiation of Spitz nevi from melanoma, but maturation at the deep margin may not be evident. Mitoses may also be present, but atypical mitoses are extremely unusual in this type of nevus and must be evaluated with caution. ${ }^{3}$ Lymphocytic inflammatory infiltrate, vascular and neural invasion can also be observed. It is questioned whether these atypical Spitz nevi are variants of melanoma. ${ }^{12}$ Unlike melanoma, Spitz nevus can show junctional cleavage (clefting), occasional and unusual epidermal invasion by solitary cells with associated hyperkeratosis, and no destruction of collagen in the dermis. ${ }^{3,4,5}$ Spitz nevus may contain epithelioid, large, round, oval or polygonal cells with similar nuclei, and fusiform cells. (Figure 8) Multinucleations can be seen.

Spindle cells are elongated, with a fusiform aspect, containing eosinophilic cytoplasm. Often the two types of cells are found in the same lesion.

The study of mitotic figures is very important and usually benign lesions do not present them. Deep mitoses are usually seen in melanoma.

Kamino bodies (eosinophilic globular bodies) usually occur in Spitz nevi (Figure 9).

\section{Atypical Spitz Nevus (or tumor)}

Usually the atypias that are founded involve the epidermis, dermis or subcutaneous tissue. These atypias may include architectural alterations or cytological atypia in the intraepidermal components. If there are dermal alterations, they involve architectural changes such as the formation of nodules, increased cellularity, asymmetry, loss of maturation, and increased mitotic activity at the base of the lesion.

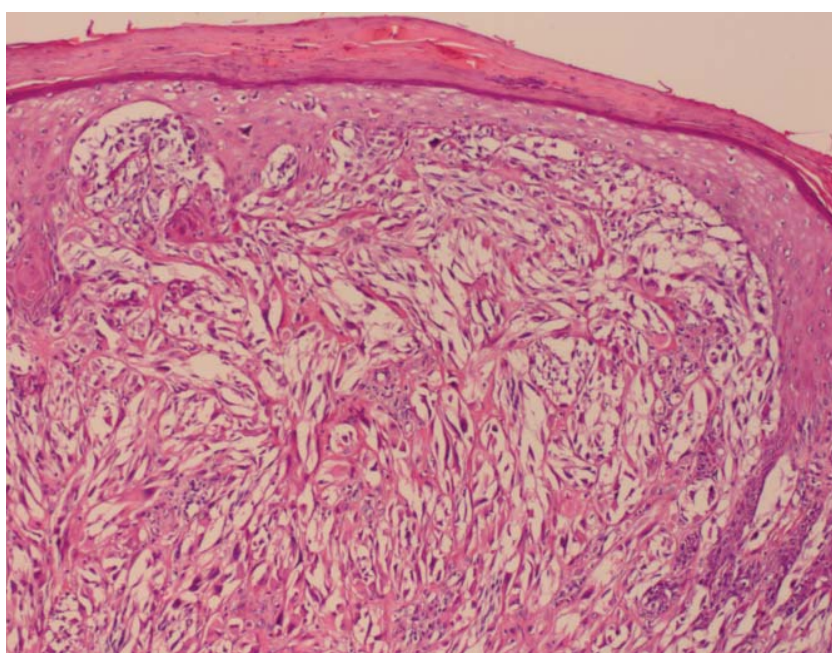

FiguRE 8: Proliferation of spindle and/or epithelioid cell nevi (HE, 100x)

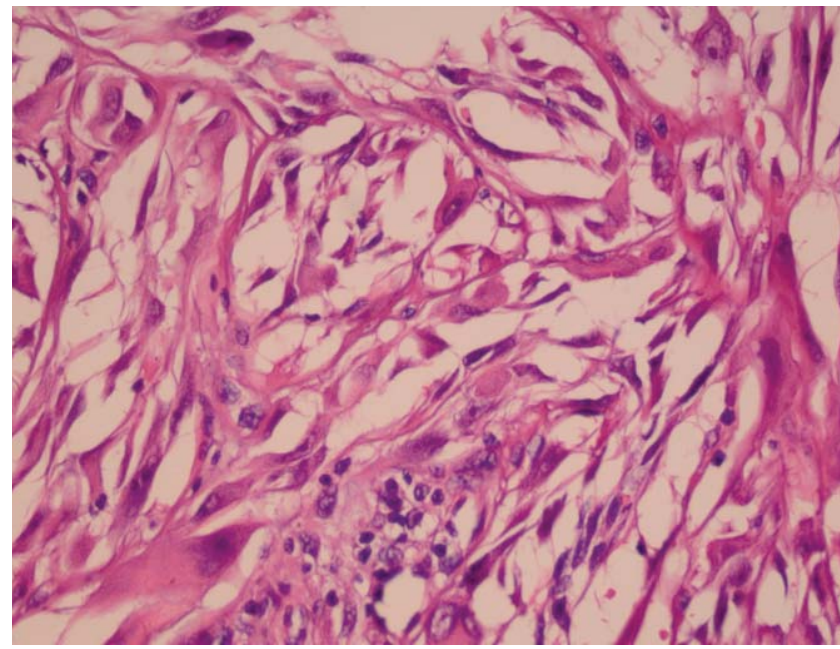

Figure 9: Presence of eosinophilic bodies (Kamino bodies) and atypical melanocytic cells (HE, 400x)

Pigmented spindle-cell nevus (Reed nevus)

Considered as a variant of Spitz nevus, it is characterized by a proliferation of highly pigmented spindle melanocytic cells, possibly containing intermingled epithelioid cells. Nests have a vertical and parallel orientation in relation to interpapillary crests (Figure 10).

This lesion tends to be predominantly intraepidermal or superficially compromise the papillary or reticular dermis. There is often transepidermal elimination of melanin through the stratum corneum. Numerous melanophages are observed in the superficial dermis. Kamino bodies can also be seen between melanocytic cells (Figure 11) ${ }^{31,32}$

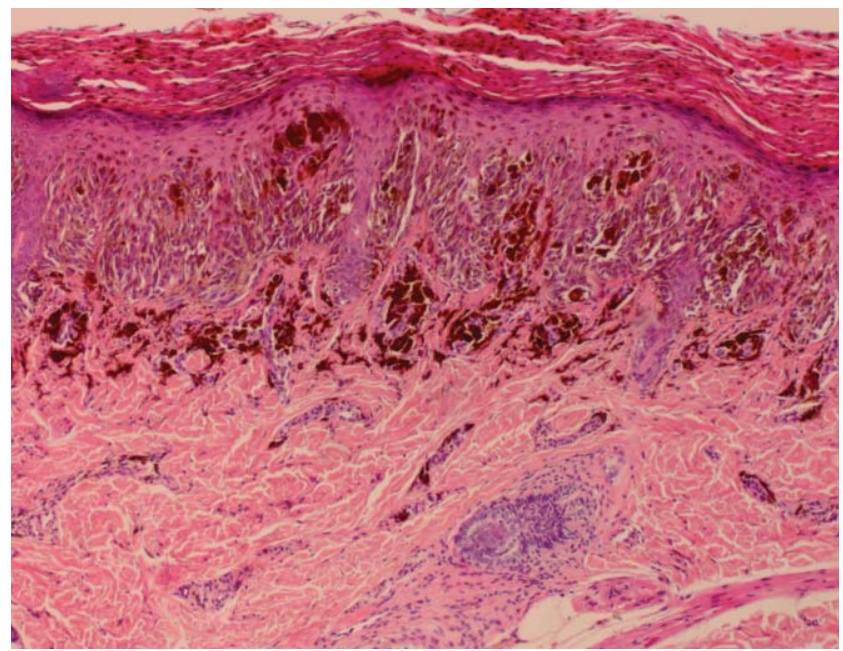

Figure 10: Panoramic view of Reed nevus. Symmetry of the lesion, abundant melanin with pigmentation of the stratum corneum and nests parallel to interpapillary ridges and perpendicular to layers of epidermal cells (HE, 40x) 


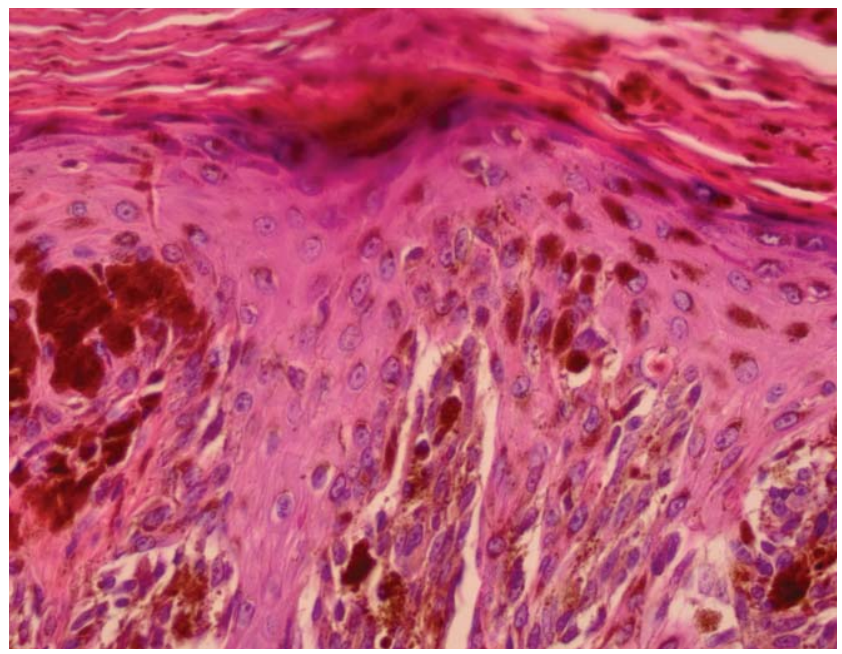

FIGURE 11: Dendritic melanocytes and Kamino body are observed in higher magnification. Nests originate from interpapillary crystals and are parallel to them (similar to "bunches of bananas") containing abundant melanin pigment (HE, 100x)

In Reed nevus, junctional cells are thin, elongated, pigmented and fusiform. Its nucleus is thin and elongated, with delicate chromatin and small nucleoli. The cells form nests and fascicles tightly grouped in the dermoepidermal junction, and they can focally infiltrate the epidermis above the basal layer of keratinocytes. Fascicles are uniform in size and expand to a widened papillary dermis, rarely reaching the reticular dermis. ${ }^{16,17}$ There may be typical mitoses and inflammation usually does not occur. In the atypical form, fascicle cells in the dermoepidermal region have larger nuclei, with evident nucleoli, and are prone to migration, which is generally confined to the uppermost portion of the tumor without lateral extension. There is also cellular hyperplasia in the basement layer, with a less defined lateral margin of the lesion, and perivascular lymphocytic infiltrate. ${ }^{11,12,17}$ The lesion is heavily pigmented by melanocytes and macrophages, which are confined to the epidermis and the papillary dermis, respectively. ${ }^{6,16}$

The main differences between the two are that in Reed nevus there is abundant melanin pigment, the monomorphism of spindle cells is more pronounced, spindle-shaped melanocytes are smaller and more uniform, with scarcity of epithelioid cells, and its growth is of the expanding rather than infiltrative type in the dermis (cell nests are confined to the epidermis or papillary dermis). Intraepidermal migration is rare, and there is a significant presence of melanin and melanophages in the dermis, in addition to a smaller amount of eosinophilic cells and mitotic figures in melanocytes. ${ }^{6,13,16}$ However, the main challenge is the differentiation of these two nevi from melanoma. ${ }^{6}$ According to some authors, criteria for such differen- tiation are symmetrical silhouette, sharp contours, maturation of melanocytes in a progressive manner to the dermis, mild pleomorphism, non-destructive infiltration of collagen, rare or inexistent mitoses, absence of atypical mitoses, irregular growth contour in the deep margins, presence of Kamino bodies (eosinophilic cells in the dermoepidermal junction first described in 1979 by Kamino, which correspond to the subsequent apoptosis of proliferating keratinocytes and melanocytes in some of these tumors), typical of spindle/epithelioid cell nevi. ${ }^{5}$ However, the distinction is often difficult when there are histological features of both nevi and melanoma, generating terms such as atypical Spitz nevus, malignant Spitz nevus and spitzoid melanoma. ${ }^{5}$ Therefore, there are reports in the literature pointing to a malignant potential of Spitz/Reed nevi. ${ }^{4}$ Such lesions would extend to the subcutaneous tissue, be larger and prone to ulceration, perhaps due to the greatest risk of local trauma. 4 There are rare cases of malignancy and metastasis, but there is doubt whether these lesions are not actually melanomas. ${ }^{6}$ Some scholars consider Spitz nevus a totally benign lesion and misdiagnosis could occur due to failure to detect subtle histological features caused by technical mistakes during biopsy, which would damage the sample and hinder histological analysis. ${ }^{9,33}$ Another consideration is whether Spitz nevus with a malignant behavior would actually be spitzoid melanoma or malignant Spitz nevus. ${ }^{33}$ The following classification has been suggested for these nevi: Spitz nevus, atypical Spitz nevus, and malignant Spitz nevus. ${ }^{33}$ A context that includes the behavior of the tumor and patient age at the time of lesion detection can make a difference in establishing the correct diagnosis. ${ }^{25,33}$ In cases where metastases have been described, they are located in the lymph nodes. In contrast to melanoma, patients with lymph node involvement showed a benign course of evolution and metastases to other organs were not described. ${ }^{4,5}$

\section{EVOLUTION, TREATMENT AND PROGNOSIS}

The scientific literature emphasizes that only histological data are not sufficient to differentiate these nevi from melanomas. Immunohistochemical markers such as S100, Mart-1/Melan A, HMB-45, tyrosinase, Mitf, Ki-67/MIB-1 and p53 may help because they are strongly positive in melanoma and show lower positivity or are absent in spindle and/or epithelioid cell nevi. However, there is no specific immunohistochemical technique for these nevi, and molecular tests (research on mutations that are more frequent in melanoma) are still the subject of studies and may be useful in the future, especially for "borderline" cases, and they may even guide the decision as to whether or not there is indication for sentinel lymph node research, 
lymphadenectomy and chemotherapy. ${ }^{8}$ Currently, the correlation of clinical diagnosis with evolutionary behavior, as well as improvement of noninvasive techniques and practices for the assessment of lesions, provides better diagnostic definition. ${ }^{5}$

In this context, dermoscopy appears as a very useful diagnostic tool. Improved diagnostic accuracy of pigmented Spitz nevi from 56 to $93 \%$ has been reported in the literature. ${ }^{18,19,28}$

There has been the recent advent of confocal microscopy, an in vivo technique that allows instant visualization of skin structures with resolution at the cellular level. There are studies showing its correlation with dermoscopic findings in Spitz nevi, which may help understand their morphology and differentiate them from other lesions. ${ }^{23}$

Atypical lesions may be associated with a more aggressive clinical course, and it is difficult to distinguish these lesions from classic spitzoid melanoma. Therefore, it is recommended that late-onset lesions in adults with features of Spitz nevus be surgically removed and sent for histopathological examination. The same applies to lesions with a rapid and/or recent change in color, shape and size. ${ }^{6,7,28,34}$ With regard to the definition of surgical margins after excisional biopsy with a 1-2 mm margin and histopathological confirmation, there is no agreement in the literature. In the case of atypical lesions, some authors recommend expanding the margin to $1 \mathrm{~cm}$. Children under 12 years of age with a classical "starburst" pattern in dermoscopy can undergo clinical and dermoscopic follow-up. ${ }^{8.34}$ In these cases of typi- cal, relatively small, symmetrical and non-ulcerated lesions, located in classical regions and in places where surgical removal may cause cosmetic damage, a careful follow-up can be conducted every 3 to 6 months. In the absence of significant changes in the appearance of the lesion (color, shape and size), this follow-up can done until the appearance of a homogeneous pattern. From then on, an annual follow-up is suggested until the complete involution of the lesion. ${ }^{34}$ Ferrara et al, in a recent article, suggest that all spitzoid lesions in children, palpable and erythematous, should be excised, especially those larger than $1 \mathrm{~cm}$, nodular, ulcerated and with a rapid evolution with changes in appearance. Excision of lesions in patients older than 12 years of age is also recommended, regardless of the presence of atypical clinical or dermoscopic features (Figure 12). ${ }^{34}$

Inadequate histological cuts of atypical lesions that appear asymmetric on clinical and dermoscopic examination my lead to incorrect diagnosis if the region of greatest asymmetry is not represented. Therefore, we suggest that the dermoscopic image be included along with the fragment excised for histopathological examination in order to orient the pathologist to make cuts in areas that are more representative of dermoscopic structures. Previous studies have shown that asymmetry is an important indicator of histopathological atypia in Spitz nevus and that this feature deserves special attention in the context of this correlation. ${ }^{7,27}$ In addition, dermoscopic examination may indicate the most suitable site for performing a biopsy of larger lesions. ${ }^{27}$

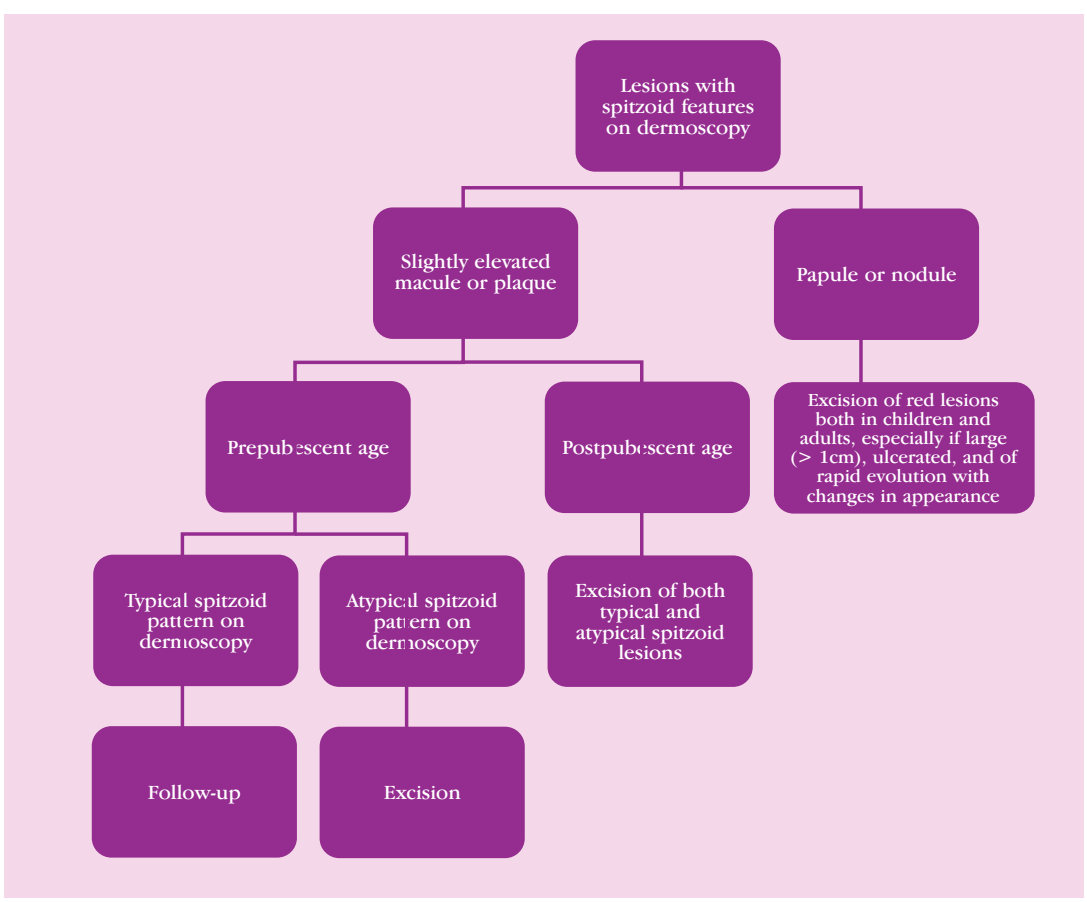


The combination of various diagnostic tools, starting with an appropriate clinical examination and including a well-executed dermoscopy with technical mastery and anatomopathological examination performed by a pathologist with experience in pigmented skin lesions will result in more reliable diagnoses, par- ticularly with respect to lesions that may mimic other lesions, indicating which is the most appropriate conduct for the patient. The greater the understanding of these nevi, the better the standardization of clinical and surgical conducts.

\section{REFERENCES}

1. Pinheiro AMC, Pereira GA, Amorin AG, Varella TCN, Friedman H. Nevo de Spitz: relato de caso e dermatoscopia. An Bras Dermatol. 2010;85:555-7.

2. Spitz S. Melanomas of childhood. Am J Pathol. 1948;24:591-609.

3. Weedon D, Little JH. Spindle and epithelioid cell nevi in children and adults. A review of 211 cases of the Spitz nevus. Cancer. 1977;40:217-25.

4. Smith KJ, Barret TL, Skelton III HG, Lupton GP, Graham JH. Spindle cell and epithelioid cell nevi with atipia and metastasis (malignant Spitz nevus). Am J Surg Pathol. 1989;13:931-9.

5. Casso EM, Grin-Jorgensen CM, Grant-Kels JM. Spitz nevi. J Am Acad Dermatol. 1992;27:901-13.

6. Peris K, Ferrari A, Argenziano G, Soyer HP, Chimenti S. Dermatoscopic classification of Spitz/Reed nevi. Clin Dermatol. 2002;20:259-62.

7. Ferrara G, Argenziano G, Soyer HP, Chimenti S, Di Biasi A, Pellacani G et al. The spectrum of Spitz nevi. A clinicopathologic study of 83 cases. Arch Dermatol. 2005;141:1381-7.

8. Lyon VB. The Spitz nevus: review and update. Clin Plastic Surg. 2010;37:21-33.

9. Shapiro PE. Spitz nevi. J Am Acad Dermatol. 1993;29:667-8.

10. Matz H, Orion E, Ruocco V, Wolf R. Clinical Simulators of Melanoma. Clin Dermatol. 2002:20:212-21.

11. Requena L, Sanchez Yus E. Pigmented spindle cell naevus. $\mathrm{Br} J$ Dermatol. 1990;123:757-63.

12. Reed RJ, Martin P. Variants of melanoma. Semin Cutan Med Surg. 1997;16:137-58.

13. Requena C, Requena L, Sánchez-Yus E, Kutzner H, Llombard B, Sammarin O, et al. Hypopigmented Reed nevus. J Cutan Pathol. 2008;35:87-9.

14. Boneti KK, Piñeiro-Maceira J, Pereira FBC, Barcaui CB. Nevo de Reed (nevo de células fusiformes): relato de três casos com padrões dermatoscópicos distintos. An Bras Dermatol. 2010;85:531-6.

15. Reed RJ, Ichinose H, Clark WH, Mihm MC. Common and uncommon melanocytic nevi and borderline melanomas. Semin Oncol. 1975;2:119-47.

16. Sagebiel RW, Chinn EK, Egbert BM. Pigmented spindle cell nevus: clinical and histologic review of 90 cases. Am J Surg Pathol. 1984;8:645-53

17. Barnhill RL, Mihm MC Jr. Pigmented spindle cell naevus and its variants: distinction from melanoma. Br J Dermatol. 1989;121:717-25.

18. Pizzichetta MA, Argenziano G, Grandi G, De Giacono C, Trevisan G, Soyer HP. Morphologic changes of pigmented Spitz nevus assessed by dermoscopy. J Am Acad Dermatol. 2002;47:137-9.

19. Steiner A, Pehamberger H, Binder M, Wolff K. Pigmented Spitz nevi: improvement of the diagnostic accuracy by epiluminescence microscopy. J Am Acad Dermatol. 1992:27:697-701.

20. Hara AYH, Hukuda N, Terui T. Usefulness of dermoscopy diagnosing pigmented Spitz nevus occuring on the glabrous skin. J Eur Acad Dermatol Venereol. 2006;20:1362-3.

21. Lage D, Hussein TP, de Mattos AC, Veríssimo RP. Nevo de Reed: lesão melanocítica benigna com feições malignas. Rev Ciênc Méd. 2006;15:455-61.

22. Argenziano G, Soyer HP, Ferrara G, Piccolo D, Hofmann-Wellenhof R, Peris K, et al. Superficial black network: an additional dermatoscopic clue for the diagnosis of pigmented spindle and/or epithelioid cell nevus. Dermatology. 2001;203:333-5.
23. Pellacani G, Cesinaro AM, Grana C, Seidenari S. In vivo confocal scanning laser microscopy of pigmented Spitz nevi: comparison of in vivo confocal images with dermoscopy and routine histopathology. J Am Acad Dermatol. 2004;51:371-6.

24. Argenziano G, Zalaudek I, Ferrara G, Lorenzoni A, Soyer HP. Involution: the natural evolution of pigmented Spitz and Reed nevi? Arch Dermatol. 2007;143:549-51.

25. Soyer HP, Kenet RO, Wolf IH, Kenet BJ, Cerroni L. Clinicopathological correlation of pigmented skin lesions using dermoscopy. Eur J Dermatol. 2000;10:22-8.

26. Ferrara G, Argenziano G, Soyer HP, Staibano S, Ruocco E, De Rosa G. Dermatoscopic-pathologic correlation: an atlas of 15 cases. Clin Dermatol. 2002;20:228-35

27. Scope A, Benvenuto-Andrade C, Agero A-L, Halpern AC, Gonzalez S, Marghoob AA Correlation of dermoscopic structures of melanocytic lesions to reflectance confocal microscopy. Arch Dermatol. 2007;143:176-85.

28. Argenziano G, Scalvenzi M, Staibano S, Brunetti B, Piccolo D, Delfino M, et al. Dermatoscopic pitfalls in differentiating pigmented Spitz naevi from cutaneous melanomas. Br J Dermatol. 1999;141:788-93

29. Marchell R, Marghoob AA, Braun RP, Argenziano G. Dermoscopy of pigmented Spitz and Reed Nevi: the starburst pattern. Arch Dermatol. 2005;141:1060.

30. Pehamberger $H$, Steiner $A$, Wolff $K$. In vivo epiluminescence microscopy of pigmented skin lesions. I. Pattern analysis of pigmented skin lesions. J Am Acad Dermatol. 1987;17:571-83.

31. Barnhill RL. Tumors of melanocytes. In: Barnhill RL, Crowson AN, Magro CMM Piepkorn MW. Dermatopathology. New York; 3rd edition; 2010. p. 632-8.

32. Magro MC, Crowson AN, Mihm MC. Benign melanocytic proliferations and precurso lesions to melanoma. In: Crowson AN, Magro CM, Mihm MC. Biopsy interpretation of the skin. Primary non-lymphoid cutaneous neoplasia. Philadelphia: Lippincott; 2009. p.43-61.

33. Piepkorn M. On the nature of histologic observations: the case of the Spitz nevus. $J$ Am Acad Dermatol. 1995;32:248-54.

34. Ferrara G, Zalaudek I, Savarese I, Scalvenzi M, Argenziano G. Pediatric atypical spitzoid neoplasms: a review with emphasison "red" ("Spitz") tumors and "blue" ("blitz") tumors. Dermatology. 2010;220:306-10.
MAILING ADDRESS:
Alessandra Yoradjian
Avenida Príncipe de Gales, 821
09060-650 Santo André, SP
E-mail: alessandraderma@botmail.com

How to cite this article: Yoradjian A, Enokihara MMSS, Paschoal FM. Spitz naevus and Reed naevus. An Bras Dermatol. 2012;87(3):349-59. 


\section{QUESTÕES}

1. Spitz nevus is clinically characterized by:

a. Often presenting as a blackened papule located in the lower limbs of young adults

b. Painful, multiple lesions that frequently ulcerate c. Usually being a single lesion, with a smooth surface, pink or reddish brown, asymptomatic, located on the face, which appears in the first two decades of life

d. Having the face as its preferred location in adults as well as in children

2. We can state the following about Spitz nevus, except: a. It has the following variants: halo, combined, dysplastic, multiple disseminated and agminated b. Caucasians are the most affected, and the disease is more frequent in women

c. The incidence of melanocytic nevi in children varies between 1 and 10\%, corresponding to $1 \%$ of the excised nevi in childhood

d. Malignant transformation and lymphatic involvement are common

3. It is incorrect to state the following about Reed nevus: a. It was originally described by Reed in 1975 and is characterized by a pigmented lesion that usually affects young women

b. It is not always a heavily pigmented lesion

c. Sometimes it becomes difficult to clinically differentiate it from Spitz nevus, and the term spindle and/or epithelioid cell nevus is a better fit for both d. It most often affects the scalp

4. It is correct to state the following about dermoscopy of spindle and/or epithelioid cell nevi:

a. Given their similarities, the technique is not useful in the differential diagnosis with melanoma

b. Little information has been obtained so far on these nevi using this technique

c. The method is not easily accessible as a diagnostic tool

d. Diagnostic accuracy can increase up to $93 \%$

5. It is correct to state the following about dermoscopy of spindle and/or epithelioid cell nevi:

a. Lesions are often asymmetric

b. The three most common patterns are starburst, globular and atypical

c. The starburst pattern is less common and is only found in initial lesions

d. The atypical pattern has its own characteristics that differentiate these nevi from melanoma

6. The dermoscopy pattern most often found in spindle and/or epithelioid cell nevi is:
a. Globular
b. Homogeneous
c. Starburst
d. Atypical

7. It is incorrect to state the following about the starburst pattern:

a. It corresponds to $53 \%$ of the cases

b. It is characterized by peripheral streaks and central globules

c. There is prominent, diffuse, bluish-gray or black central pigmentation, with radiate streaks on the periphery

d. The streaks correspond to small compressed cell nests

8. We can state the following about spindle and/or epithelioid cell nevi:

a. The atypical dermoscopic pattern, found in $25 \%$ of the cases, may have the appearance of a bluish-white veil and "black blotches" which can make the differential diagnosis with melanoma difficult

b. In hypopigmented Spitz nevus, a typical finding in dermoscopy is the blue-white veil

c. As it happens on clinical examination, it is impossible to differentiate spindle and/or epithelioid cell nevi from melanoma on dermoscopy

d. Globules correspond to small cell nests on the center of the lesion

9. It is correct to state the following about the superficial black network, except:

a. It may be found in up to $10.5 \%$ of the cases and is considered a unique feature, useful for the diagnosis of Spitz and Reed nevi

b. It corresponds to the typical honeycomb-like pattern of the pigment network

c. It is a structure that resembles the pigment net work, being prominent and black, with a bluish and more diffuse background

d. On histopathological examination, it corresponds to focal areas of pigmented parakeratosis due to increased melanin production by melanocyte nests

10. It is correct to state the following:

a. Reverse pigment network is a pathognomonic finding of melanoma

b. Spitz nevi are precursor lesions of melanoma and should always be excised

c. There are cases in which the differential diagnosis of spindle and/or epithelioid cell nevi with melanoma is difficult, especially in the atypical forms

d. Hypopigmented Spitz and Reed nevi are easily distinguishable from melanoma

11. The following is known about the evolution of spindle and/or epithelioid cell nevi:

a. They can reach large dimensions and present with an infiltrative character with local tissue destruction and even lymphatic involvement

b. After their onset, they remain stable without any changes throughout the patient's life

c. Hypopigmented Spitz nevus evolves into pigmented nevus, being then called Reed nevus d. It is common for them to disappear over the years, which would explain the absence of recognition in older individuals 
12. It is correct to state the following about the progression model of evolution suggested by Pizzechetta:

a. It proposes that Spitz and Reed nevi would progressively change from the globular to the starburst pattern, and then to a homogeneous pattern until its complete disappearance

b. The patterns are steps in the evolutionary process of the same lesion

c. It explains why Spitz and Reed nevi are mostly seen in children and young adults

d. All of the above.

13. The following can be observed in the histopathological examination of Spitz nevi:

a. Most of these nevi are located in the dermis

b. Asymmetry, atypia and necrosis, which can make differential diagnosis with melanoma difficult, are very common

c. They are usually compound nevi

d. Immature cells and mitotic figures are common findings at the base of the lesion

14. It is correct to state the following:

a. Kamino bodies are eosinophilic globular formations that usually occur in Spitz nevi

b. Reed nevus is characterized by predominance of epithelioid cells

c. Involvement of the subcutaneous tissue is common in Reed nevus

$\mathrm{d}$. There is a higher number of spindle cells in Spitz nevus

15. We can state the following about the histopathological differences between Reed and Spitz nevi:

a. There is abundant melanin pigment in Reed nevus as compared with Spitz nevus

b. In Reed nevus there is predominance of spindle cells, and cellular monomorphism is less frequent in Spitz nevus

c. Their differentiation is irrelevant, and the main issue is the differential diagnosis with melanoma

d. All of the above.

16. The following are criteria proposed for the differentiation of spindle and/or epithelioid cell nevi with melanoma, except:

a. Symmetry and absence of mitosis

b. Melanocyte maturation in the dermis

c. Kamino bodies

d. Presence of melanophages

17. It is incorrect to state the following about Spitz nevi: a. Spitz nevus is a lesion that is considered benign and there is speculation that cases with malignant behavior could actually be spitzoid melanoma

b. It is important to consider the age of onset of the disease in the evaluation of the patient

c. There may be involvement of lymph nodes and metastases to other organs

d. Due to controversy, the following classification has been suggested: Spitz nevus, atypical Spitz nevus and malignant Spitz nevus
18. It is possible to state the following about the diagnosis of spindle and/or epithelioid cell nevi:

a. Histopathology allows the differential diagnosis with melanoma in $100 \%$ of the cases

b. For adequate diagnosis, the correlation between clinical examination, evolutionary data and dermos copy is necessary

c. There are specific immunohistochemical markers for these nevi, which are important in their differentiation from melanoma

d. All of the above

19. It is correct to state the following about the medical conduct in relation to spindle and/or epithelioid cell nevi: a. There is no agreement in the literature, but in cases in which the evolutionary data show significant changes in appearance, excisional biopsy with a 1-2 $\mathrm{mm}$ margin is recommended

b. Lesions in adults should be surgically removed c. In children younger than 12 years whose lesion shows the "starburst" pattern on dermoscopy, with classical location and symmetry, follow up can be done every 3 to 6 months d. All of the above.

20. It is incorrect to state the following about the dermoscopic-histopathologic correlation of spindle and/or epithelioid cell nevi:

a. Asymmetric lesions should have the region of grea test asymmetry represented in histological cuts b. It is quite useful to combine the dermoscopic image with the excised fragment, as this can orient the pathologist to make the most appropriate histological cuts

c. Dermoscopy can indicate the site of greatest atypia in asymmetrical lesions

d. It is recommended to perform incisonal biopsy of suspicious lesions regardless of their size

\section{Answer key of the quiz on Tuberous Sclerosis Complex}

$2012 ; 87(2): 184-96$.

$\begin{array}{llllllll}1- & \text { d } & 6- & \text { A } & 11- & \text { D } & 16- & \text { C } \\ \text { 2- } & \text { C } & 7- & \text { B } & 12- & \text { C } & 17- & \text { A } \\ \text { 3- } & \text { B } & 8- & \text { A } & 13- & \text { C } & 18- & \text { B } \\ \text { 4- } & \text { D } & 9- & \text { D } & 14- & \text { A } & 19- & \text { A } \\ \text { 5- } & \text { D } & 10- & \text { B } & 15- & \text { D } & 20- & \text { D }\end{array}$

\section{AVISO}

Caros associados, para responder ao questionário de EMC-D, por favor, acessem o site dos Anais Brasileiros de Dermatologia. O prazo para responder é de 30 dias a partir da publicação online no link a seguir, www.anaisdedermatologia.org.br 